-, MArshall, G. N., Boyd, J. L. et al (1983) Relapse in schizophrenia: a review of the concept and its definitions. Psychological Medicine, 7, 469-477.

\section{Toxicity of antidepressants}

SIR: Beaumont (Journal, April 1989, 154, 454-458) has contributed in an imaginative way to the debate concerning the prescription of antidepressant medication. The principal issue reviewed in his article is that of toxicity in overdose.

A number of authors have addressed the issue of calculating the relative risk of fatal poisoning associated with antidepressants, notably Leonard (1986) and Cassidy \& Henry (1987). While there is no definitive way of arriving at a calculation which will precisely predict the pattern of fatalities following overdosage with antidepressant agents (since the necessary data is unavailable), these authors provide a 'fatal toxicity index' which attempts to predict the number of deaths per million prescriptions of each drug.

The results are striking, and perhaps can be illustrated even more clearly by the extrapolations below. The total number of prescriptions for antidepressant medications in 1987, in the UK, was around 7009000 (Pers. Comm., ICI Pharmaceuticals). We can therefore use Cassidy \& Henry's formula to predict that if only a single antidepressant agent were to be administered throughout the UK, we could expect the following consequences: exclusive use of dothiepin would result in 350 deaths per annum; amitriptyline, 326; and doxepin, 219. In contrast, use of the 'newer' antidepressants would compare as follows: trazodone, 95 deaths per annum; and lofepramine, 0 . Since the body of evidence available would suggest little difference in efficacy between the spectrum of antidepressant agents, the justification for using the older, more toxic antidepressants seems tenuous. Additionally, the newer compounds have superior adverse effect profiles.

In the light of current political developments, we are likely to be subjected to progressively greater pressure to 'rationalise' our prescribing habits. Our fear is that this will involve the production of Regional Health Board and hospital formularies which will attempt to restrict our antidepressant prescribing to that of the cheapest products available. Already, in the Grampian area, we are being urged to use amitriptyline, imipramine, and doxepin.

We agree that there seems little need to use other than a small fraction of the antidepressant medications available to us. However, we suggest that restricting our clinical freedom to the use of lofepramine, trazodone, one of the serotonin re-uptake blockers, and a single MAOI (for example phenelzine) might substantially reduce the 'human cost' of our prescribing.

We are faced with balancing financial considerations against those of fatality in overdose. Since doctors are generally poor at predicting suicide attempts (Barraclough et al, 1974), it is currently inevitable that our patients will continue to kill themselves with the tools which we supply. Which is the greater cost?

\section{Kingseat Hospital}

Newmachar

The Ross Clinic

Cornhill Road

Aberdeen AB9 2ZF

KeIth MatTHEWS

John M. EAgLeS

\section{References}

Barraclough, B., Bunch, J., Nelson, B., et al (1974) A hundred cases of suicide: clinical aspects. British Journal of Psychiatry. $125,355-373$.

Cassidy, S. \& Henrry, J. (1987) Fatal toxicity of antidepressant drugs in overdosage. British Medical Journal, 295, 1021-1024.

LEONARD, B. E. (1986) Toxicity of antidepressants. Lancet, ii, 1105.

\section{Toxicity of hospital water?}

SIR: We have recently reported (King \& Birch, 1989) that toxic concentrations of heavy metals in drinking water may occur at Victorian mental hospitals with independent water supplies. The problem is compounded by compulsive water drinking among chronically psychotic patients, which is often difficult to detect and is probably under-diagnosed (Noonan \& Ananth, 1977; Lee et al, 1989). Heavy metal neurotoxicity masquerading as psychiatric illness seems a real possibility in some of our institutions, especially where maintenance has been neglected.

We are unsure how widespread such hazards are in practice, and should be interested in hearing from anyone working in older hospitals where discoloured water may indicate corroded pipework.

\section{Barnsley Hall Hospital}

Bromsgrove

Worcestershire B617AX

J. R. KING

N. J. BIRCH

\section{References}

KING, J. R. \& BIRCH, N. J. (1989) Health hazards on tap. Lancet, $i$, 1080.

LeE, S., Chow, C. C. \& Koo, L. C. L. (1989) Altered state of consciousness in a compulsive water drinker. British Journal of Psychiatry, 154, 556-558. 